\title{
Presynaptic Glycine Receptors Increase GABAergic Neurotransmission in Rat Periaqueductal Gray Neurons
}

\author{
Kwi-Hyung Choi, Michiko Nakamura, and Il-Sung Jang \\ Department of Pharmacology, School of Dentistry, Kyungpook National University, Daegu 700-412, Republic of Korea \\ Correspondence should be addressed to Il-Sung Jang; jis7619@mail.knu.ac.kr
}

Received 24 May 2013; Revised 6 July 2013; Accepted 31 July 2013

Academic Editor: Dong-ho Youn

Copyright ( 2013 Kwi-Hyung Choi et al. This is an open access article distributed under the Creative Commons Attribution License, which permits unrestricted use, distribution, and reproduction in any medium, provided the original work is properly cited.

\begin{abstract}
The periaqueductal gray (PAG) is involved in the central regulation of nociceptive transmission by affecting the descending inhibitory pathway. In the present study, we have addressed the functional role of presynaptic glycine receptors in spontaneous glutamatergic transmission. Spontaneous EPSCs (sEPSCs) were recorded in mechanically dissociated rat PAG neurons using a conventional whole-cell patch recording technique under voltage-clamp conditions. The application of glycine $(100 \mu \mathrm{M})$ significantly increased the frequency of sEPSCs, without affecting the amplitude of sEPSCs. The glycine-induced increase in sEPSC frequency was blocked by $1 \mu \mathrm{M}$ strychnine, a specific glycine receptor antagonist. The results suggest that glycine acts on presynaptic glycine receptors to increase the probability of glutamate release from excitatory nerve terminals. The glycine-induced increase in sEPSC frequency completely disappeared either in the presence of tetrodotoxin or $\mathrm{Cd}^{2+}$, voltage-gated $\mathrm{Na}^{+}$, or $\mathrm{Ca}^{2+}$ channel blockers, suggesting that the activation of presynaptic glycine receptors might depolarize excitatory nerve terminals. The present results suggest that presynaptic glycine receptors can regulate the excitability of PAG neurons by enhancing glutamatergic transmission and therefore play an important role in the regulation of various physiological functions mediated by the PAG.
\end{abstract}

\section{Introduction}

Glycine, in addition to GABA, is the primary inhibitory neurotransmitter in the brain stem and spinal cord. In mature neurons, the inhibitory action of glycine is accomplished by activating strychnine-sensitive glycine receptors and opening $\mathrm{Cl}^{-}$channels, which results in membrane shunting or hyperpolarization of postsynaptic neurons [1]. Glycine receptors are found in most of brain areas including the hippocampus, amygdala, ventral tegmental area, and periaqueductal gray (PAG) [2-5]. Nevertheless, functional roles of glycine receptors are largely unknown because glycine is unlikely to be released from presynaptic nerve terminals, and there is no direct evidence for glycinergic inhibitory postsynaptic currents in these brain structures (but see also [6]). However, previous studies have shown that endogenous glycine and/or taurine can elicit the tonic $\mathrm{Cl}^{-}$currents mediated by glycine receptors in central neurons [5, 7], suggesting that endogenous glycine and/or taurine may play a role in the regulation of neuronal excitability. On the other hand, glycine receptors are also found in presynaptic nerve terminals of many brain regions, and their activation is known to facilitate neurotransmitter release from presynaptic nerve terminals [8-11]. In these cases, presynaptic glycine receptors might regulate the neuronal excitability in an indirect manner via the presynaptic modulation of neurotransmitter release.

The PAG is involved in the various functions including pain, vocalization, fear and anxiety, lordosis, and cardiovascular control $[12,13]$. In particular, the PAG plays a crucial role in the regulation of nociceptive transmission as the PAG is one of regulatory centers affecting the endogenous descending inhibitory pathway such as noradrenergic and serotonergic systems [13]. In fact, electrical stimulation of the PAG region reduces neuropathic pain by activating the descending inhibitory system $[14,15]$. In addition, the PAG is known to be one of the target sites for opioids and cannabinoids $[16,17]$. On the other hand, it has been well established that several neurotransmitters including glutamate and 
GABA within the PAG are responsible for the regulation of nociceptive transmission $[13,18]$. Of them, glycine is likely to play a role in the processing of pain within the PAG, as glycine is inversely correlated to nociceptive paw stimulation [19]. However, a significant amount of the glycine released within the PAG seems to act on glycine sites of NMDA receptors rather than strychnine-sensitive glycine receptors [20-22], indicating that the functional roles of glycine receptors in the PAG are still largely unknown. In the present study, therefore, we have investigated whether functional glycine receptors exist on glutamatergic nerve terminals projecting to PAG neurons and whether their activation modulates spontaneous glutamatergic transmission.

\section{Materials and Methods}

2.1. Preparation. All experiments complied with the guiding principles for the care and use of animals approved by the Council of the Physiological Society of Korea and the National Institutes of Health Guide for the Care and Use of Laboratory Animals, and every effort was made to minimize both the number of animals used and their suffering.

Sprague Dawley rats (12-16 d old, either sex) were decapitated under ketamine anesthesia $(100 \mathrm{mg} / \mathrm{kg}$, i.p.). The midbrain was dissected and transversely sliced at a thickness of $400 \mu \mathrm{m}$ using a microslicer (VT1000S; Leica, Nussloch, Germany). The midbrain slices containing the PAG were kept in an incubation solution (in $\mathrm{mM}: 124 \mathrm{NaCl}, 3 \mathrm{KCl}$, $1.5 \mathrm{KH}_{2} \mathrm{PO}_{4}, 24 \mathrm{NaHCO}_{3}, 2 \mathrm{CaCl}_{2}, 1.3 \mathrm{MgSO}_{4}$, and 10 glucose) saturated with $95 \% \mathrm{O}_{2}$ and $5 \% \mathrm{CO}_{2}$ at room temperature $\left(22-24^{\circ} \mathrm{C}\right)$ for at least $1 \mathrm{~h}$ before the mechanical dissociation. For dissociation, slices were transferred into a $35 \mathrm{~mm}$ culture dish (Primaria 3801; Becton Dickinson, Rutherford, NJ, USA) containing a standard external solution (in $\mathrm{mM}: 150 \mathrm{NaCl}$, $3 \mathrm{KCl}, 2 \mathrm{CaCl}_{2}, 1 \mathrm{MgCl}_{2}, 10$ glucose, 10 Hepes, and $\mathrm{pH} 7.4$ with Tris-base), and the PAG region was identified under a binocular microscope (SMZ-1; Nikon, Tokyo, Japan). Details of the mechanical dissociation have been described previously $[23,24]$. Briefly, mechanical dissociation was accomplished using a custom-built vibration device and a fire-polished glass pipette oscillating at about $50-60 \mathrm{~Hz}(0.3-0.5 \mathrm{~mm})$ on the surface of the ventrolateral PAG region. Slices were removed and the mechanically dissociated neurons were left for $15 \mathrm{~min}$ to allow the neurons to adhere to the bottom of the culture dish.

\subsection{Electrophysiology. All electrophysiological measure-} ments were performed using conventional whole-cell patch recording mode at holding potentials $\left(V_{\mathrm{H}}\right.$ values) of -60 to $-65 \mathrm{mV}$, which are the reversal potential of glycine-induced membrane currents determined in every PAG neurons, except where indicated (Axopatch 200B; Molecular Devices, Union City, CA, USA). Patch pipettes were made from borosilicate capillary glass $(1.5 \mathrm{~mm}$ outer diameter, $0.9 \mathrm{~mm}$ inner diameter; G-1.5; Narishige, Tokyo, Japan) by use of a pipette puller (P-97; Sutter Instrument Co., Novato, CA, USA). The tip of pipette was firstly filled with the Cs-methanesulfonate-based internal solution (in mM: 140 Cs-methanesulfonate, 10CsCl, 2 EGTA, 5 QX314, 2 ATP-Mg, 10 Hepes, and pH 7.2 with Tris-base) using a capillary phenomenon, and then the CsF-based internal solution, in which Cs-methanesulfonate was replaced with equimolar CsF, was backfilled using a syringe. The resistance of the recording pipettes filled with these internal solutions was $4-6 \mathrm{M} \Omega$. The liquid junction potential $(\sim-11 \mathrm{mV}$, measured by exchanging bath solution from internal solution to standard external solution) and pipette capacitance were compensated for. Neurons were viewed under phase contrast on an inverted microscope (TE2000; Nikon). Membrane currents were filtered at $2 \mathrm{kHz}$, digitized at $5 \mathrm{kHz}$, and stored on a computer equipped with pCLAMP 10.2 (Molecular Devices). During the recordings, $10 \mathrm{mV}$ hyperpolarizing step pulses (30 $\mathrm{ms}$ in duration) were periodically applied to monitor the access resistance. All experiments were performed at room temperature $\left(22-25^{\circ} \mathrm{C}\right)$.

2.3. Data Analysis. Spontaneous excitatory postsynaptic currents (sEPSCs) were counted and analyzed using the MiniAnalysis program (Synaptosoft, Inc., Decatur, GA, USA) as described previously [25]. Briefly, sEPSCs were screened automatically using an amplitude threshold of $10 \mathrm{pA}$ and then were visually accepted or rejected based upon the rise and decay times. Basal noise levels during voltage-clamp recordings were typically less than $8 \mathrm{pA}$. The average values of the frequency, amplitude, and decay time constant (90$37 \%$ ) of sEPSCs during the control period or each drug condition ( $5 \mathrm{~min}$ ) were calculated for each recording, and the frequency and amplitude of all the events during the glycine application (1-2 $\mathrm{min}$ ) were normalized to these values. The effects of these different conditions were quantified as a percentage increase in sEPSC frequency compared to the control values. The interevent intervals and amplitudes of a large number of synaptic events obtained from the same neuron were examined by constructing cumulative probability distributions and compared using the Kolmogorov-Smirnov (K-S) test with Stat View software (SAS Institute, Inc., Cary, NC, USA). Numerical values are expressed as the mean \pm standard error of the mean (SEM) using values normalized to the control. Significant differences in the mean amplitude and frequency were tested using Student's paired two-tailed $t$-test, using absolute values rather than normalized ones. Values of $P<0.05$ were considered significant.

2.4. Drugs. The drugs used in the present study were glycine, strychnine, 6-imino-3-(4-methoxyphenyl)-1(6H)pyridazinebutanoic acid $\mathrm{HBr}$ (SR95531), tetrodotoxin (TTX), 6-cyano-7-nitroquinoxaline-2,3-dione (CNQX), DL-2amino-5-phosphonovaleric acid (APV), QX-314, EGTA, $\mathrm{CdCl}_{2}$, and ATP-Mg (from Sigma, St. Louis, MO, USA). The standard external solution routinely contained $10 \mu \mathrm{M}$ SR95531 and APV $50 \mu \mathrm{M}$ APV to block $\mathrm{GABA}_{\mathrm{A}}$ and NMDA receptors, respectively. All solutions containing drugs were applied using the "Y-tube system" for rapid solution exchange [26]. 


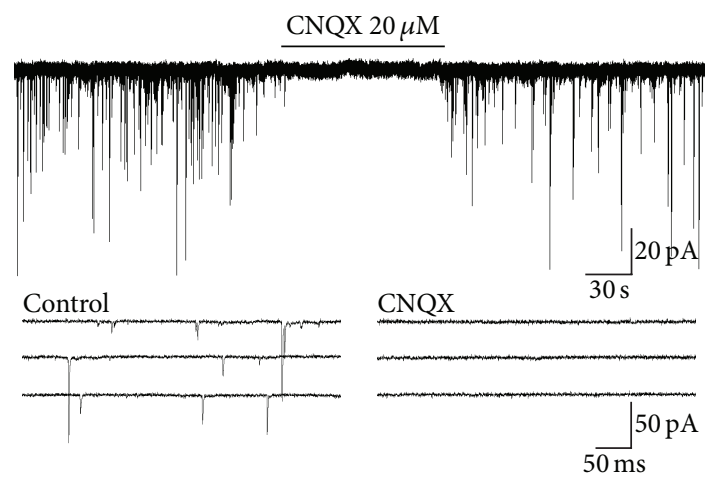

(a)

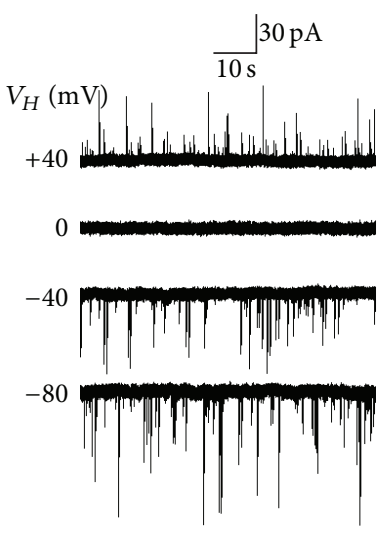

(A)

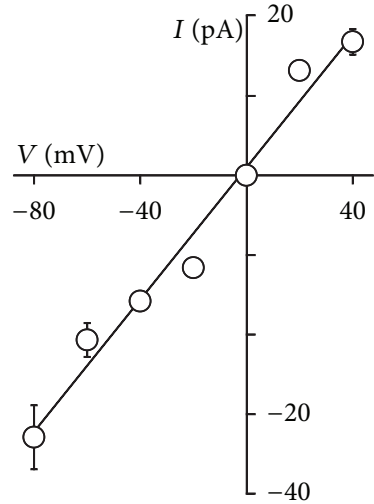

(B)

(b)

FIGURE 1: Glutamatergic sEPSCs recorded from acutely isolated PAG neurons. (a) A typical trace of glutamatergic sEPSCs observed before, during, and after application of $20 \mu \mathrm{M} \mathrm{CNQX}$, an AMPA/KA receptor blocker, at a $V_{H}$ of $0 \mathrm{mV}$ in the presence of $10 \mu \mathrm{M}$ SR95531 and $50 \mu \mathrm{M}$ $\mathrm{APV}$, selective $\mathrm{GABA}_{\mathrm{A}}$, and NMDA receptor antagonists, respectively. Insets represent typical traces with an expanded time scale. (b) (A) Typical traces of glutamatergic sEPSCs at various holding potentials $\left(V_{\mathrm{H}}\right)$. (B) A plot of the mean amplitude of sEPSCs at various $V_{\mathrm{H}}$ values. The reversal potential was $-2.5 \mathrm{mV}$, which is close to the theoretical equilibrium potential of monovalent cations. Each point was the mean and SEM from the 4 neurons.

\section{Results}

After brief mechanical dissociation of the ventrolateral PAG region, several kinds of neurons that differed in soma diameter $(10-15 \mu \mathrm{m})$ and shape (multipolar, bipolar, and pyramidalshaped) were found. These morphological properties of acutely isolated neurons were similar to those of PAG neurons identified in previous studies $[27,28]$. When these neurons were held at a $V_{\mathrm{H}}$ of $-60 \mathrm{mV}$ using the whole-cell patch-clamp technique, the spontaneous inward synaptic currents were recorded in the presence of both $10 \mu \mathrm{M}$ SR95531 and $50 \mu \mathrm{M}$ $\mathrm{APV}$, selective $\mathrm{GABA}_{\mathrm{A}}$ and $\mathrm{NMDA}$, and receptor antagonists, respectively. These spontaneous inward currents were completely and reversibly blocked by $20 \mu \mathrm{M}$ CNQX $(n=5)$, an AMPA/KA receptor blocker (Figure 1(a)). Figure 1(b) shows typical raw traces recorded at various $V_{\mathrm{H}}$ conditions and the current-voltage relationship $(n=4)$. The reversal potential for the spontaneous synaptic currents was estimated from the current-voltage relationship to be $-2.5 \mathrm{mV}$. This value is very similar to the theoretical equilibrium potential of monovalent cations. These results indicate that the spontaneous synaptic events recorded from acutely isolated PAG neurons were AMPA/KA receptor-mediated sEPSCs.

To investigate whether excitatory nerve terminals projecting to PAG neurons express functional glycine receptors and whether the activation of presynaptic glycine receptors directly modulates spontaneous glutamate release, we observed the effect of exogenously applied glycine on sEPSCs. The glycine receptor-mediated membrane currents were minimized by using the CsF-based pipette solution and by adjusting the $V_{\mathrm{H}}$ to experimentally determined reversal potential of glycine-induced currents. In these conditions, glycine $(100 \mu \mathrm{M})$ rapidly and reversibly increased the frequency of glutamatergic sEPSCs (Figure 2(a)). In 12 neurons for which the effect was fully analyzed, glycine $(100 \mu \mathrm{M})$ increased sEPSC frequency to $429.7 \pm 33.9 \%$ of the control $(0.81 \pm 0.18 \mathrm{~Hz}$ for control and $3.48 \pm 0.27 \mathrm{~Hz}$ for glycine, $P<$ $0.01)$, without affecting sEPSC amplitude $(98.3 \pm 5.9 \%$ of the control, $23.1 \pm 1.9 \mathrm{pA}$ for control, and $22.7 \pm 1.6 \mathrm{pA}$ for glycine, $P=0.57$; Figures 2(a) and 2(b) insets). In addition, glycine significantly shifted the cumulative distribution of interevent interval to the left $(P<0.01, \mathrm{~K}-\mathrm{S}$ test, Figure $2(\mathrm{~b})(\mathrm{A}))$ without affecting the cumulative distribution of the current amplitude $(P=0.13$, K-S test, Figure 2(b) $(\mathrm{B}))$, consistent with an increase in the frequency of glutamatergic sEPSCs. Glycine also did not affect the decay time constant of glutamatergic sEPSCs $(2.21 \pm 0.12 \mathrm{~ms}$ of the control and $2.19 \pm 0.13 \mathrm{~ms}$ for glycine, $P=0.96$; Figure 2 (a) inset). Taken together, these results suggest that glycine acts presynaptically to increase spontaneous glutamate release onto acutely isolated PAG neurons.

To investigate whether the glycine-induced increase in spontaneous glutamate release is mediated by presynaptic glycine receptors, we observed the effect of strychnine, a specific glycine receptor antagonist, on the glycine-induced increase in sEPSC frequency. Strychnine $(1 \mu \mathrm{M})$ by itself had no effect on the basal frequency $(111.6 \pm 10.3 \%$ of the control, $n=6, P=0.31)$ or amplitude $(97.6 \pm 8.5 \%$ of the control, $n=$ $6, P=0.21$ ) of glutamatergic sEPSCs (Figures 3(a) and 3(b)). In the presence of $1 \mu \mathrm{M}$ strychnine, the facilitatory action of glycine $(418.1 \pm 38.3 \%$ of the control, $n=6, P<0.01)$ was completely attenuated to $88.4 \pm 9.2 \%$ of the strychnine condition ( $n=6, P=0.42$, Figures $3(\mathrm{a})$ and $3(\mathrm{~b})(\mathrm{A}))$.

Next, the possible mechanisms underlying the glycineinduced increase in spontaneous glutamate release were examined. Since the activation of presynaptic glycine receptors facilitates spontaneous neurotransmitter release by eliciting a presynaptic depolarization [9-11], we observed 


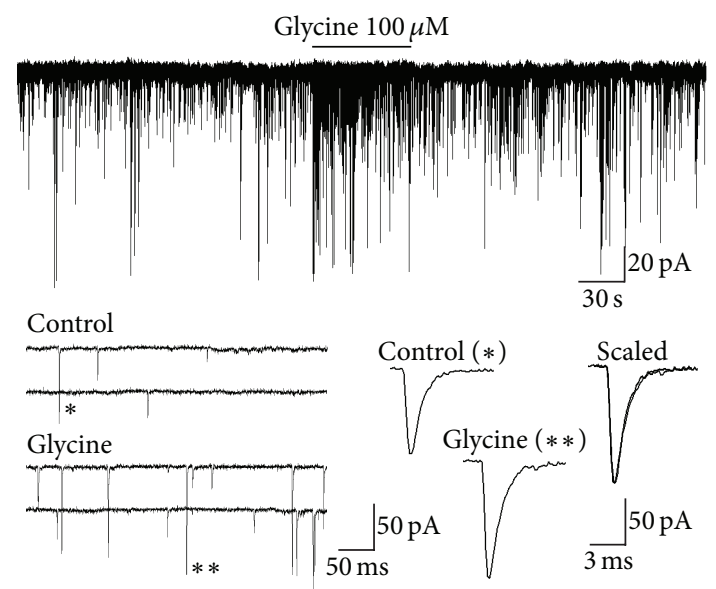

(a)

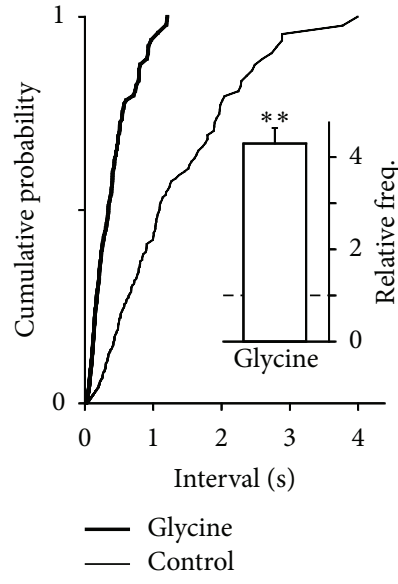

(A)

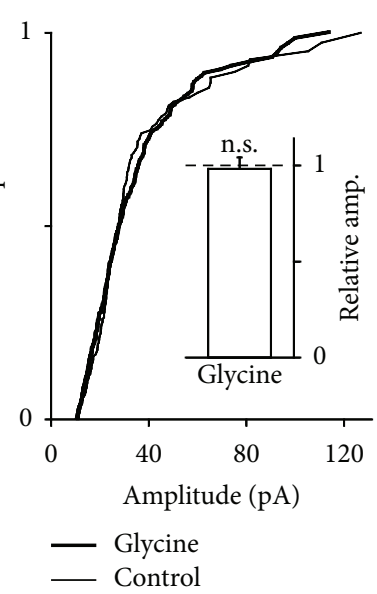

(B)

(b)

FIGURE 2: Effects of glycine on glutamatergic sEPSCs. (a) A typical trace of glutamatergic sEPSCs observed before, during, and after application of $100 \mu \mathrm{M}$ glycine. Insets represent typical traces with an expanded time scale (left) and single sEPSCs indicated by symbols (right). (b) Cumulative probability distribution for interevent interval (A) and current amplitude (B) of glutamatergic sEPSCs. 191 for control (thin lines) and 292 events for glycine (thick lines) were plotted. Insets column represents mean and SEM from 12 neurons. Dotted lines represent the relative control of basal frequency and amplitude of sEPSCs. ${ }^{* *} P<0.01$; n.s.: not significant.

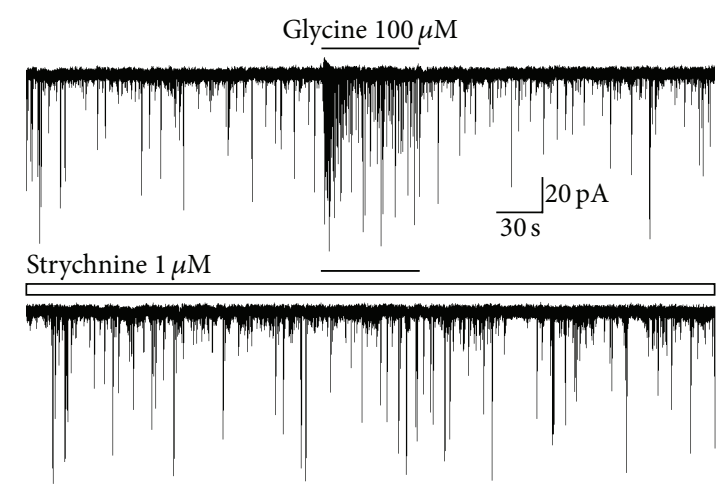

(a)

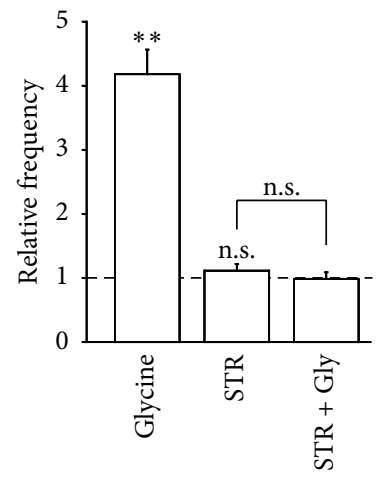

(A)

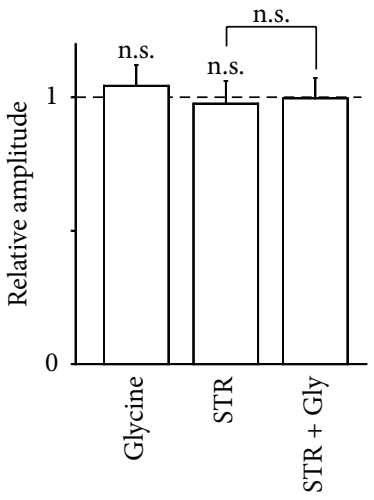

(B)

(b)

FIGURE 3: Effect of strychnine on glycine-induced increase in sEPSC frequency. (a) Typical traces of glutamatergic sEPSCs observed during the application of $100 \mu \mathrm{M}$ glycine in the absence (upper) and presence (lower) of $1 \mu \mathrm{M}$ strychnine. (b) Glycine-induced changes in frequency (A) and amplitude (B) of sEPSC in the absence and presence of strychnine. Each column was the mean and SEM from 6 neurons. ${ }^{* *} P<0.01$; n.s.: not significant.

the effect of TTX, a voltage-dependent $\mathrm{Na}^{+}$channel blocker, on the glycine-induced increase in sEPSCs frequency. The application of $300 \mathrm{nM}$ TTX significantly decreased the basal sEPSC frequency $(64.4 \pm 4.6 \%$ of the control, $n=6, P<0.01$, Figures 4(a) and 4(b)(A)), but it had no effect on the basal sEPSC amplitude $(98.9 \pm 8.1 \%$ of the control, $n=6, P=0.17$, Figures 4(a) and 4(b)(B)). In the presence of $300 \mathrm{nM}$ TTX, the facilitatory action of glycine $(458.6 \pm 39.1 \%$ of the control, $n=6, P<0.01)$ was completely occluded to $103.7 \pm 11.0 \%$ of the TTX condition $(n=6, P=0.55$, Figures $4(\mathrm{a})$ and $4(\mathrm{~b})(\mathrm{A}))$.
The neurotransmitter release is triggered by an increase in the intraterminal $\mathrm{Ca}^{2+}$ concentration, which is generally accomplished by presynaptic voltage-dependent $\mathrm{Ca}^{2+}$ channels (VDCCs) [29]. Therefore, we further examined the effect of $\mathrm{Cd}^{2+}$, a general VDCC blocker, on the glycine-induced increase in sEPSCs frequency. The application of $200 \mu \mathrm{M}$ $\mathrm{Cd}^{2+}$ also significantly decreased the basal sEPSC frequency $(61.1 \pm 5.5 \%$ of the control, $n=6, P<0.01$, Figures 4(a) and $4(\mathrm{~b})(\mathrm{A}))$. However, $\mathrm{Cd}^{2+}$ did not affect the basal sEPSC amplitude $(96.2 \pm 8.8 \%$ of the control, $n=6, P=0.61$, Figures 5(a) and 5(b)(B)). In the presence of $200 \mu \mathrm{M} \mathrm{Cd}^{2+}$, 


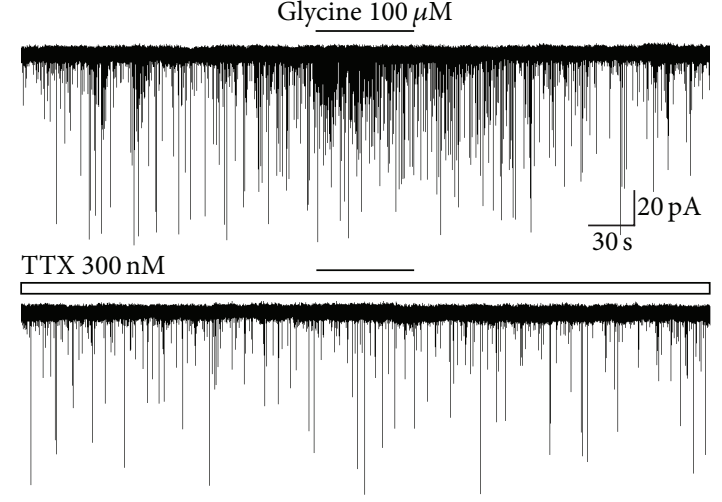

(a)

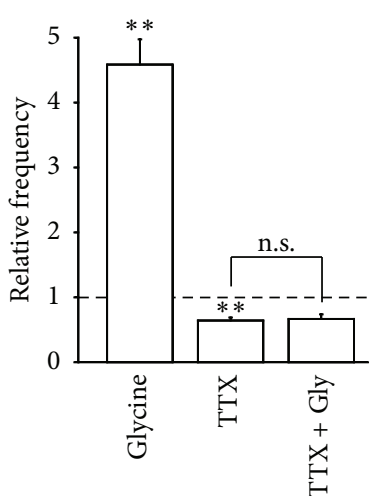

(A)

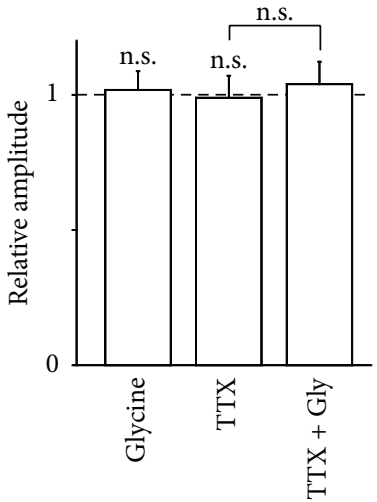

(B)

(b)

FIGURE 4: Effect of TTX on glycine-induced increase in sEPSC frequency. (a) Typical traces of glutamatergic sEPSCs observed during the application of $100 \mu \mathrm{M}$ glycine in the absence (upper) and presence (lower) of $300 \mathrm{nM}$ TTX. (b) Glycine-induced changes in frequency (A) and amplitude (B) of sEPSC in the absence and presence of TTX. Note that the glycine-induced facilitation of sEPSC frequency was completely suppressed by TTX. Each column was the mean and SEM from 7 neurons. ${ }^{* *} P<0.01$; n.s.: not significant.

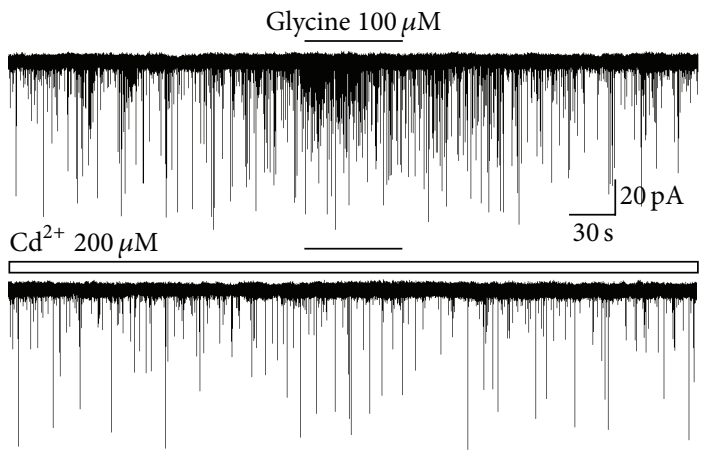

(a)

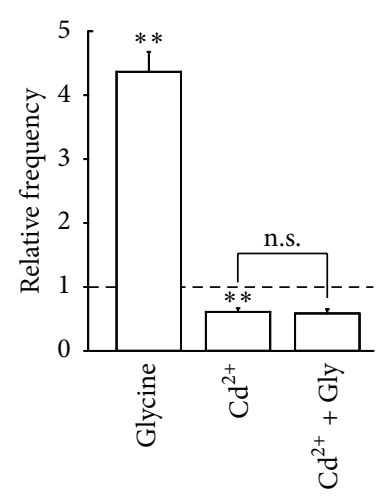

(A)

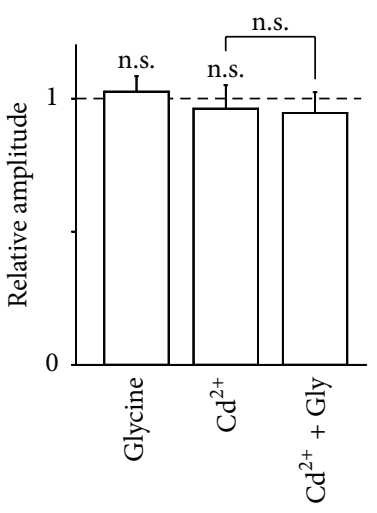

(B)

(b)

FIGURE 5: Effect of $\mathrm{Cd}^{2+}$ on glycine-induced increase in sEPSC frequency. (a) Typical traces of glutamatergic sEPSCs observed during the application of $100 \mu \mathrm{M}$ glycine in the absence (upper) and presence (lower) of $200 \mu \mathrm{M} \mathrm{Cd}^{2+}$. (b) Glycine-induced changes in frequency (A) and amplitude (B) of sEPSC in the absence and presence of $\mathrm{Cd}^{2+}$. Note that the glycine-induced facilitation of sEPSC frequency was completely suppressed by $\mathrm{Cd}^{2+}$. Each column was the mean and SEM from 7 neurons. ${ }^{* *} P<0.01$; n.s.: not significant.

the facilitatory action of glycine $(436.8 \pm 31.1 \%$ of the control, $n=6, P<0.01)$ was completely occluded to $95.9 \pm 10.6 \%$ of the $\mathrm{Cd}^{2+}$ condition $(n=6, P=0.28$, Figures $5(\mathrm{a})$ and $5(\mathrm{~b})(\mathrm{B}))$.

\section{Discussion}

Previous studies have shown that glycine receptors are expressed on presynaptic nerve terminals at central synapses and that their activation modulates the presynaptic release of a variety of neurotransmitters, such as glutamate $[8$, 11], GABA [10], and glycine [9]. Several lines of evidence suggest that glycine receptors are also expressed on excitatory nerve terminals projecting to PAG neurons and that their activation enhances spontaneous glutamate release onto PAG neurons. First, glycine significantly increased the frequency of sEPSCs without affecting the current amplitude, consistent with a presynaptic locus of glycine action. Second, this facilitatory action of glycine on glutamatergic sEPSCs was completely blocked by strychnine. Although presynaptic $\mathrm{GABA}_{\mathrm{A}}$ receptors also enhance spontaneous glutamate release at these synapses [30], the involvement of presynaptic $\mathrm{GABA}_{\mathrm{A}}$ receptors should be negligible because the present study was performed after the blockade of $\mathrm{GABA}_{\mathrm{A}}$ receptors with SR95531. In addition, since the extracellular solution contained APV, a specific NMDA receptor antagonist, the involvement of possible NMDA receptors should be also negligible. Third, the preparation used in this study would 
support a presynaptic locus of glycine action because dissociated neurons have presynaptic nerve terminals without their parent soma [24].

In the present study, we found that glycine failed to enhance sEPSC frequency in the presence of either TTX or $\mathrm{Cd}^{2+}$, suggesting that the glycine-induced increase in sEPSC frequency requires the activation of voltagedependent $\mathrm{Na}^{+}$and $\mathrm{Ca}^{2+}$ channels. That is, the activation of presynaptic glycine receptors might depolarize excitatory nerve terminals, and that this presynaptic depolarization seems to activate voltage-dependent $\mathrm{Na}^{+}$and $\mathrm{Ca}^{2+}$ channels subsequently. In addition, since glycine had no facilitatory effect on spontaneous glutamate release in the presence of TTX, the extent of glycine receptor-mediated presynaptic depolarization might be not enough to activate VDCCs directly [25, 31]. Alternatively, glycine receptors might be expressed on preterminal region so that the glycine receptormediated depolarization would affect voltage-dependent $\mathrm{Na}^{+}$ rather than $\mathrm{Ca}^{2+}$ channels at axons. Similarly, nicotinic acetylcholine receptors expressed on the axonal region are known to enhance spontaneous neurotransmitter release in a TTXsensitive manner [32]. On the other hand, given that glycine receptors are permeable to $\mathrm{Cl}^{-}$but not cations and that the activation of glycine receptors elicits a presynaptic depolarization; excitatory nerve terminals projecting to PAG neurons might maintain higher intraterminal $\mathrm{Cl}^{-}$concentration than that predicted for passive $\mathrm{Cl}^{-}$distribution. This can be accomplished by the inwardly directed $\mathrm{Cl}^{-}$cotransporters such as bumetanide-sensitive $\mathrm{Na}^{+}-\mathrm{K}^{+}-2 \mathrm{Cl}^{-}$cotransporter type 1 [33, 34]. Similarly, we have previously shown that bumetanidesensitive $\mathrm{Na}^{+}-\mathrm{K}^{+}-2 \mathrm{Cl}^{-}$cotransporter type 1 maintains the higher $\mathrm{Cl}^{-}$concentration within presynaptic nerve terminals $[25,35]$. In this regard, since the $\mathrm{Cl}^{-}$concentration within the neuronal soma becomes lower with postnatal development by changing the expression of $\mathrm{Cl}^{-}$cotransporters [36], it is of interest to examine whether the expression of presynaptic $\mathrm{Cl}^{-}$cotransporters as well as the glycine receptor-mediated presynaptic modulation alters during postnatal development.

As PAG neurons project their excitatory axon terminals directly to serotonergic and noradrenergic neurons of the medulla, which innervate their fibers the superficial dorsal horn [37], the excitability of PAG neurons should be a key factor involved in the PAG-mediated descending inhibitory systems. For example, microinjection of the $\mathrm{GABA}_{\mathrm{A}}$ receptor antagonists or glutamate into the PAG shows antinociceptive responses in animal models [38-40]. In addition, opioid analgesics seem to disinhibit tonically active GABAergic neurons within the PAG [41], suggesting that an increase in the excitability of output PAG neurons produces analgesia. In this regard, glycine might be also involved in the regulation of excitability of PAG neurons. For example, a previous study has shown that the microinjection of glycine into the dorsal PAG of rats increases tail-flick latencies in a dose-dependent manner, and this hyponociceptive effect of glycine is reversed by coadministration with the specific inhibitor for NMDA receptor glycine site [42], suggesting that microinjected glycine acts on glycine-binding site of NMDA receptors to elicit hyponociception. In addition, a recent study has shown that the microinjection of glycine into the ventrolateral PAG of rats produces conflicting results, for example, hyperalgesia or analgesia [43]. In this study, while the glycine-induced analgesia is blocked by the NMDA receptor antagonist, the glycine-induced hyperalgesia is blocked by the glycine receptor antagonist [43], suggesting that glycine acts as an excitatory transmitter, for example, coagonist for NMDA receptors, to increase the excitability of output PAG neurons. In the case of glycine-induced hyperalgesia, the activation of glycine receptors, presumably somatodendritic and/or postsynaptic glycine receptors, might result from the decrease in the excitability of output PAG neurons. Although the source of extracellular glycine remains to be elucidated, glycine might be synaptically released as described previously [44]. It should be noted that, however, postsynaptic glycine receptors are unlikely to contribute to the regulation of neuronal excitability, as inhibitory postsynaptic currents are absolutely mediated by $\mathrm{GABA}_{\mathrm{A}}$ receptors rather than strychnine-sensitive glycine receptors [45].

In the present study, we have shown that the activation of presynaptic glycine receptors increases spontaneous glutamate release onto PAG neurons via a presynaptic depolarization. The present results would provide a physiological role of presynaptic glycine receptors in the antinociceptive function mediated by the PAG, as the activation of presynaptic glycine receptors can increase the excitability of PAG neurons by enhancing excitatory glutamatergic transmission. This speculation might be different from previous findings showing that glycine microinjected into the PAG produces hyperalgesic action in a strychnine-sensitive manner [43]. However, the previous behavioral findings might be not applicable to the present study because the microinjected glycine can activate somatodendritic as well as presynaptic glycine receptors within the PAG region. Although it is still unknown whether the glycine-induced hyperalgesia is mediated by somatodendritic or presynaptic glycine receptors, somatodendritic glycine receptors might be responsible for the microinjected glycine-induced hyperalgesia. This is because the glycineinduced hyperpolarization decreases the excitability of output PAG neurons, as described above. In fact, PAG neurons express functional somatodendritic glycine receptors, and the application of glycine to isolated PAG neurons elicits large $\mathrm{Cl}^{-}$currents [46]. Further electrophysiological and behavioral studies will be needed to elucidate the differential roles of somatodendritic and presynaptic glycine receptors in the regulation of nociceptive transmission mediated by the PAG.

\section{Conclusions}

In conclusion, we have shown that functional glycine receptors are expressed on glutamatergic nerve terminals projecting to PAG neurons and that the activation of presynaptic glycine receptors depolarizes presynaptic terminals to enhance spontaneous glutamate release. The present results suggest that presynaptic glycine receptors can regulate the excitability of PAG neurons by enhancing glutamatergic transmission and therefore play an important role in the 
regulation various physiological functions mediated by the PAG.

\section{Acknowledgments}

This research was supported by Basic Science Research Program through the National Research Foundation of Korea (NRF) funded by the Ministry of Education, Science and Technology (2012R1A2A2A02046812 and 2012-0009327). K.-H. Choi and M. Nakamura have equally contributed to this work.

\section{References}

[1] J. W. Lynch, "Molecular structure and function of the glycine receptor chloride channel," Physiological Reviews, vol. 84, no. 4, pp. 1051-1095, 2004.

[2] B. A. McCool and J. S. Farroni, "Subunit composition of strychnine-sensitive glycine receptors expressed by adult rat basolateral amygdala neurons," European Journal of Neuroscience, vol. 14, no. 7, pp. 1082-1090, 2001.

[3] F. Wang, C. Xiao, and J. H. Ye, "Taurine activates excitatory nonsynaptic glycine receptors on dopamine neurones in ventral tegmental area of young rats," Journal of Physiology, vol. 565, no. 2, pp. 503-516, 2005.

[4] B. I. Min, C. J. Kim, J. S. Rhee, and N. Akaike, "Modulation of glycine-induced chloride current in acutely dissociated rat periaqueductal gray neurons by $\mu$-opioid agonist, DAGO," Brain Research, vol. 734, no. 1-2, pp. 72-78, 1996.

[5] L. H. Zhang, N. Gong, D. Fei, L. Xu, and T. L. Xu, "Glycine uptake regulates hippocampal network activity via glycine receptor-mediated tonic inhibition," Neuropsychopharmacology, vol. 33, no. 3, pp. 701-711, 2008.

[6] A. A. Ghavanini, D. A. Mathers, and E. Puil, "Glycinergic inhibition in thalamus revealed by synaptic receptor blockade," Neuropharmacology, vol. 49, no. 3, pp. 338-349, 2005.

[7] M. Mori, B. H. Gähwiler, and U. Gerber, “ $\beta$-Alanine and taurine as endogenous agonists at glycine receptors in rat hippocampus in vitro," Journal of Physiology, vol. 539, no. 1, pp. 191-200, 2002.

[8] R. Turecek and L. O. Trussell, "Presynaptic glycine receptors enhance transmitter release at a mammalian central synapse," Nature, vol. 411, no. 6837, pp. 587-590, 2001.

[9] H. J. Jeong, I. S. Jang, A. J. Moorhouse, and N. Akaike, "Activation of presynaptic glycine receptors facilitates glycine release from presynaptic terminals synapsing onto rat spinal sacral dorsal commissural nucleus neurons," Journal of Physiology, vol. 550, no. 2, pp. 373-383, 2003.

[10] J. H. Ye, F. Wang, K. Krnjević, W. Wang, Z. G. Xiong, and J. Zhang, "Presynaptic glycine receptors on GABAergic terminals facilitate discharge of dopaminergic neurons in ventral tegmental area," Journal of Neuroscience, vol. 24, no. 41, pp. 8961-8974, 2004.

[11] E. A. Lee, J. H. Cho, I. S. Choi et al., "Presynaptic glycine receptors facilitate spontaneous glutamate release onto hilar neurons in the rat hippocampus," Journal of Neurochemistry, vol. 109, no. 1, pp. 275-286, 2009.

[12] M. M. Behbehani, "Functional characterstics of the midbrain periaqueductal gray," Progress in Neurobiology, vol. 46, no. 6, pp. 575-605, 1995.

[13] M. J. Millan, "Descending control of pain," Progress in Neurobiology, vol. 66, no. 6, pp. 355-474, 2002.
[14] D. V. Reynolds, "Surgery in the rat during electrical analgesia induced by focal brain stimulation," Science, vol. 164, no. 3878, pp. 444-445, 1969.

[15] R. Monhemius, D. L. Green, M. H. T. Roberts, and J. Azami, "Periaqueductal grey mediated inhibition of responses to noxious stimulation is dynamically activated in a rat model of neuropathic pain," Neuroscience Letters, vol. 298, no. 1, pp. 70$74,2001$.

[16] T. L. Yaksh, "Pharmacology and mechanisms of opioid analgesic activity," Acta Anaesthesiologica Scandinavica, vol. 41, no. 1, pp. 94-111, 1997.

[17] D. P. Finn, M. D. Jhaveri, S. R. G. Beckett et al., "Effects of direct periaqueductal grey administration of a cannabinoid receptor agonist on nociceptive and aversive responses in rats," Neuropharmacology, vol. 45, no. 5, pp. 594-604, 2003.

[18] M. M. Behbehani and H. L. Fields, "Evidence that an excitatory connection between the periaqueductal gray and nucleus raphe magnus mediates stimulation produced analgesia," Brain Research, vol. 170, no. 1, pp. 85-93, 1979.

[19] S. Maione, I. Marabese, F. S. Rossi et al., "Effects of persistent nociception on periaqueductal gray glycine release," Neuroscience, vol. 97, no. 2, pp. 311-316, 2000.

[20] L. Berrino, S. Vitagliano, S. Maione, E. Lampa, and F. Rossi, "Modulation by glycine on vascular effects of NMDA: in vivo experimental research," Amino Acids, vol. 5, no. 2, pp. 239-244, 1993.

[21] E. Viu, A. Zapata, J. L. Capdevila, L. H. Fossom, P. Skolnick, and R. Trullas, "Glycine site antagonists and partial agonists inhibit N-methyl-D-aspartate receptor-mediated $[3 \mathrm{H}]$ arachidonic acid release in cerebellar granule cells," Journal of Pharmacology and Experimental Therapeutics, vol. 285, no. 2, pp. 527-532, 1998.

[22] M. A. Martins, A. P. Carobrez, and C. R. Tonussi, "Activation of dorsal periaqueductal gray by glycine produces long lasting hyponociception in rats without overt defensive behaviors," Life Sciences, vol. 83, no. 3-4, pp. 118-121, 2008.

[23] J. S. Rhee, H. Ishibashi, and N. Akaike, "Calcium channels in the GABAergic presynaptic nerve terminals projecting to Meynert neurons of the rat," Journal of Neurochemistry, vol. 72, no. 2, pp. 800-807, 1999.

[24] N. Akaike and A. J. Moorhouse, "Techniques: applications of the nerve-bouton preparation in neuropharmacology," Trends in Pharmacological Sciences, vol. 24, no. 1, pp. 44-47, 2003.

[25] I. S. Jang, H. J. Jeong, S. Katsurabayashi, and N. Akaike, "Functional roles of presynaptic GABAA receptors on glycinergic nerve terminals in the rat spinal cord," Journal of Physiology, vol. 541, no. 2, pp. 423-434, 2002.

[26] K. Murase, P. D. Ryu, and M. Randic, "Excitatory and inhibitory amino acids and peptide-induced responses in acutely isolated rat spinal dorsal horn neurons," Neuroscience Letters, vol. 103, no. 1, pp. 56-63, 1989.

[27] P. W. Mantyh, "The midbrain periaqueductal gray in the rat, cat, and monkey: a Nissl, Weil, and Golgi analysis," Journal of Comparative Neurology, vol. 204, no. 4, pp. 349-363, 1982.

[28] A. J. Beitz and R. D. Shepard, "The midbrain periaqueductal gray in the rat. II. A Golgi analysis," Journal of Comparative Neurology, vol. 237, no. 4, pp. 460-475, 1985.

[29] L. G. Wu and P. Saggau, "Presynaptic inhibition of elicited neurotransmitter release," Trends in Neurosciences, vol. 20, no. 5, pp. 204-212, 1997. 
[30] I. S. Jang, "GABAA receptors facilitate spontaneous glutamate release in rat periaqueductal gray neurons," NeuroReport, vol. 22, no. 16, pp. 834-838, 2011.

[31] M. M. Dorostkar and S. Boehm, "Presynaptic lonotropic receptors," Handbook of Experimental Pharmacology, vol. 184, pp. 479-527, 2008.

[32] M. Alkondon, E. F. R. Pereira, H. M. Eisenberg, and E. X. Albuquerque, "Choline and selective antagonists identify two subtypes of nicotinic acetylcholine receptors that modulate GABA release from CAl interneurons in rat hippocampal slices," Journal of Neuroscience, vol. 19, no. 7, pp. 2693-2705, 1999.

[33] G. H. Clayton, G. C. Owens, J. S. Wolff, and R. L. Smith, "Ontogeny of cation- $\mathrm{Cl}^{-}$cotransporter expression in rat neocortex," Developmental Brain Research, vol. 109, no. 2, pp. 281292, 1998.

[34] M. D. Plotkin, E. Y. Snyder, S. C. Hebert, and E. Delpire, "Expression of the $\mathrm{Na}-\mathrm{K}-2 \mathrm{Cl}$ cotransporter is developmentally regulated in postnatal rat brain: a possible mechanism underlying GABA's excitatory role in immature brain," Journal of Neurobiology, vol. 33, no. 6, pp. 781-795, 1997.

[35] I. S. Jang, H. J. Jeong, and N. Akaike, "Contribution of the Na$\mathrm{K}-\mathrm{Cl}$ cotransporter on GABAA receptor-mediated presynaptic depolarization in excitatory nerve terminals," Journal of Neuroscience, vol. 21, no. 16, pp. 5962-5972, 2001.

[36] C. Rivera, J. Voipio, J. A. Payne et al., “The $\mathrm{K}^{+} / \mathrm{Cl}^{-}$co-transporter KCC2 renders GABA hyperpolarizing during neuronal maturation," Nature, vol. 397, no. 6716, pp. 251-255, 1999.

[37] A. A. Cameron, I. A. Khan, K. N. Westlund, and W. D. Willis, "The efferent projections of the periaqueductal gray in the rat: a Phaseolus vulgaris-leucoagglutinin study. II. Descending projections," Journal of Comparative Neurology, vol. 351, no. 4, pp. 585-601, 1995.

[38] J. L. Moreau and H. L. Fields, "Evidence for GABA involvement in midbrain control of medullary neurons that modulate nociceptive transmission," Brain Research, vol. 397, no. 1, pp. 37-46, 1986.

[39] J. Sandkuhler, E. Willmann, and Q. G. Fu, "Blockade of GABA(A) receptors in the midbrain periaqueductal grey abolishes nociceptive spinal dorsal horn neuronal activity," European Journal of Pharmacology, vol. 160, no. 1, pp. 163-166, 1989.

[40] E. Carstens, M. Hartung, B. Stelzer, and M. Zimmermann, "Suppression of a hind limb flexion withdrawal reflex by microinjection of glutamate or morphine into the periaqueductal gray in the rat," Pain, vol. 43, no. 1, pp. 105-112, 1990.

[41] A. Depaulis, M. M. Morgan, and J. C. Liebeskind, "GABAergic modulation of the analgesic effects of morphine microinjected in the ventral periaqueductal gray matter of the rat," Brain Research, vol. 436, no. 2, pp. 223-228, 1987.

[42] M. A. Martins, A. P. Carobrez, and C. R. Tonussi, "Activation of dorsal periaqueductal gray by glycine produces long lasting hyponociception in rats without overt defensive behaviors," Life Sciences, vol. 83, no. 3-4, pp. 118-121, 2008.

[43] E. Palazzo, F. Guida, A. Migliozzi et al., "Intraperiaqueductal gray glycine and $\mathrm{D}$-serine exert dual effects on rostral ventromedial medulla On- and Off-cell activity and thermoceptive threshold in the rat," Journal of Neurophysiology, vol. 102, no. 6, pp. 3169-3179, 2009.

[44] V. de Novellis, I. Marabese, R. Uliano et al., "Type I and II metabotropic glutamate receptors modulate periaqueductal grey glycine release: interaction between mGlu2/3 and $\mathrm{A} 1$ adenosine receptors," Neuropharmacology, vol. 43, no. 7, pp. 1061-1069, 2002.

[45] M. Nakamura and I. S. Jang, "Presynaptic nicotinic acetylcholine receptors enhance GABAergic synaptic transmission in rat periaqueductal gray neurons," European Journal of Pharmacology, vol. 640, no. 1-3, pp. 178-184, 2010.

[46] B. I. Min, C. J. Kim, J. S. Rhee, and N. Akaike, "Modulation of glycine-induced chloride current in acutely dissociated rat periaqueductal gray neurons by $\mu$-opioid agonist, DAGO," Brain Research, vol. 734, no. 1-2, pp. 72-78, 1996. 

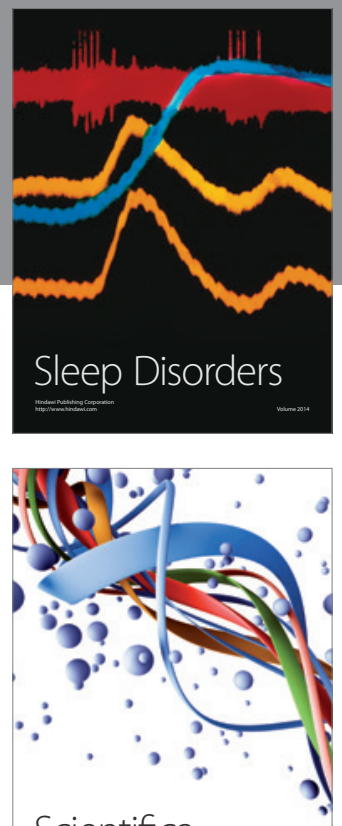

Scientifica
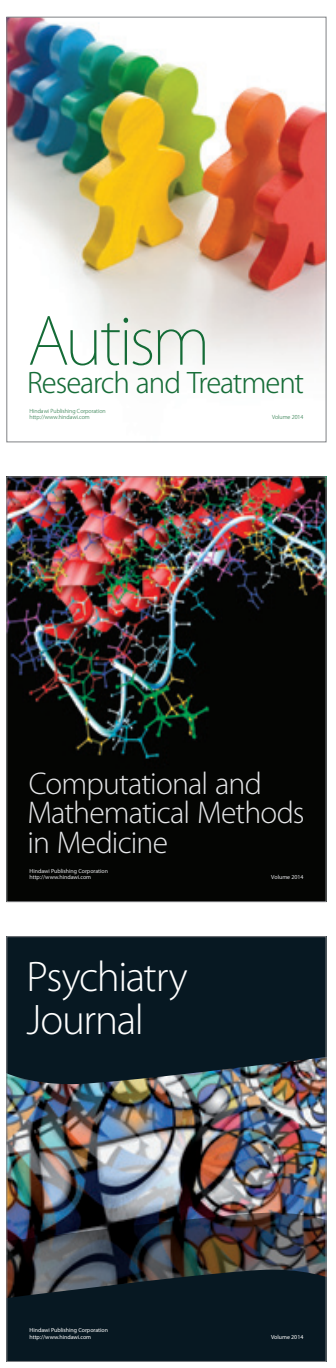
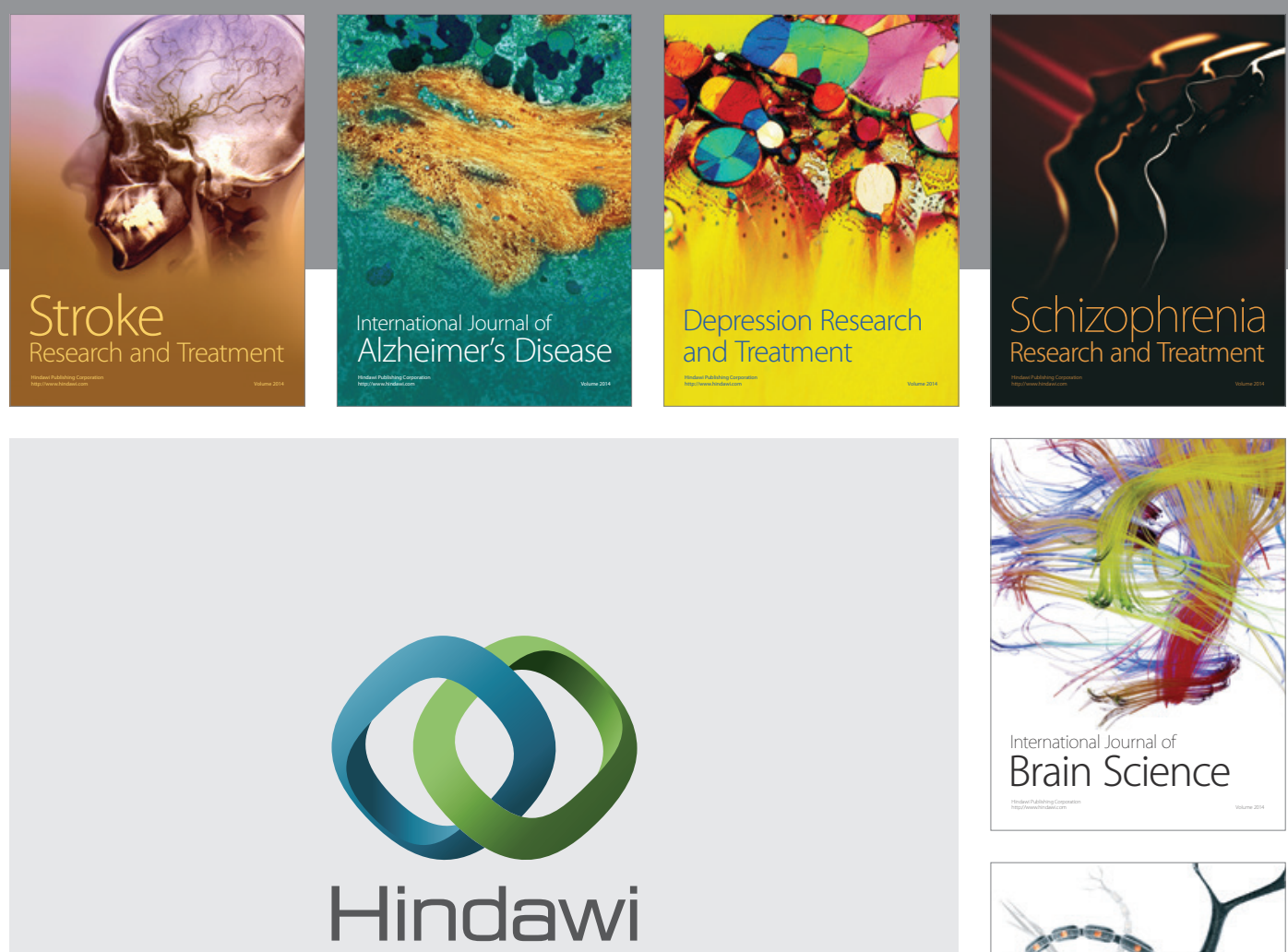

Submit your manuscripts at

http://www.hindawi.com
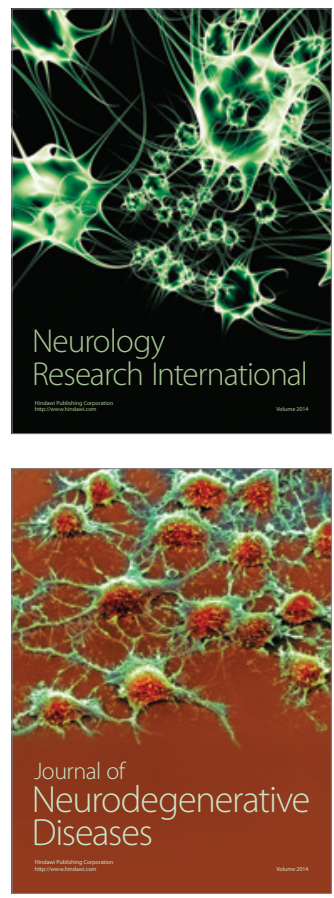

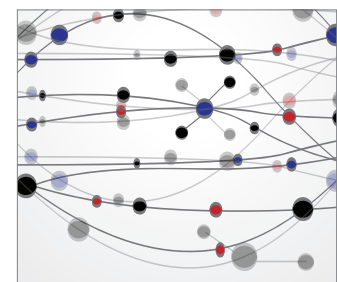

The Scientific World Journal
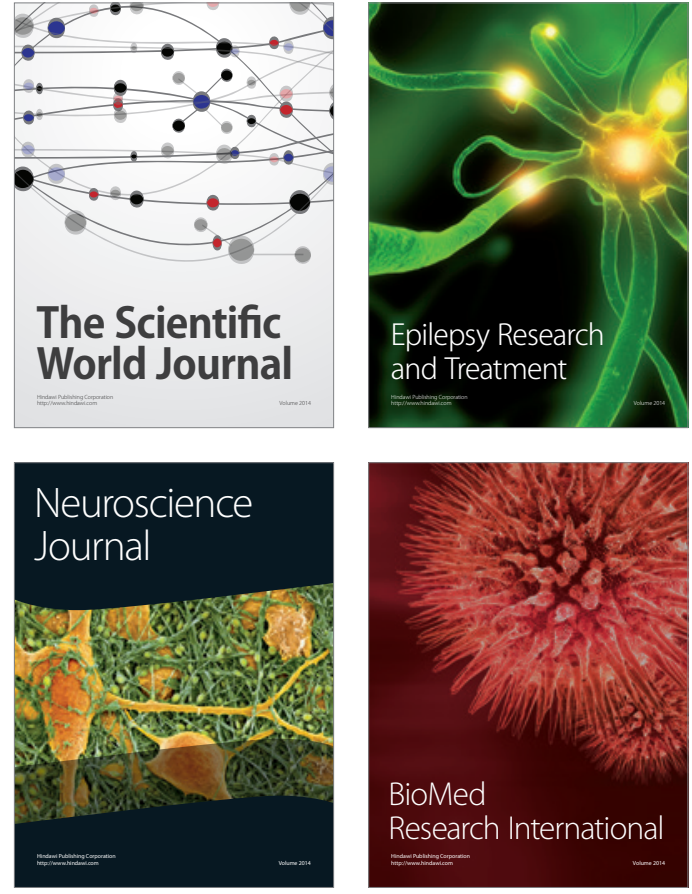

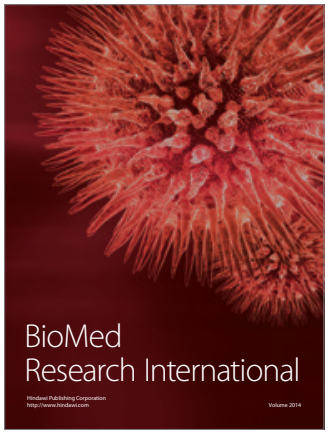

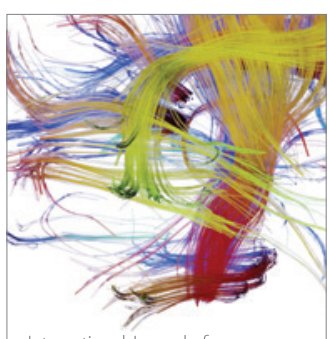

Brain Science

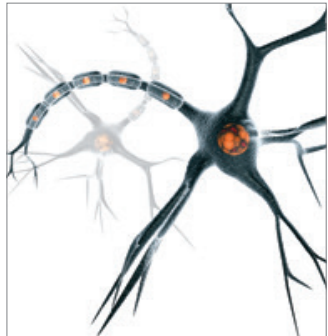

Neural Plasticity
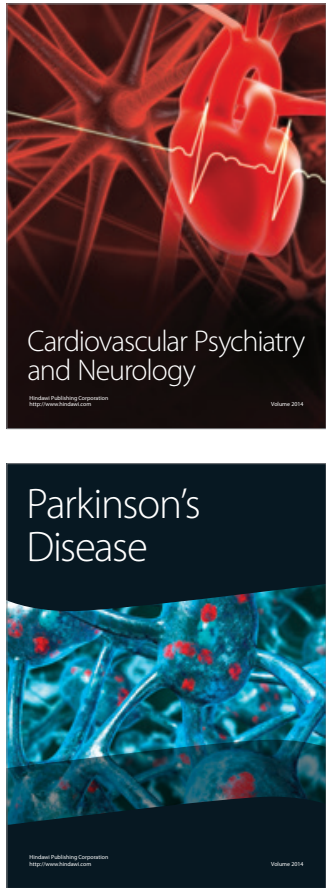